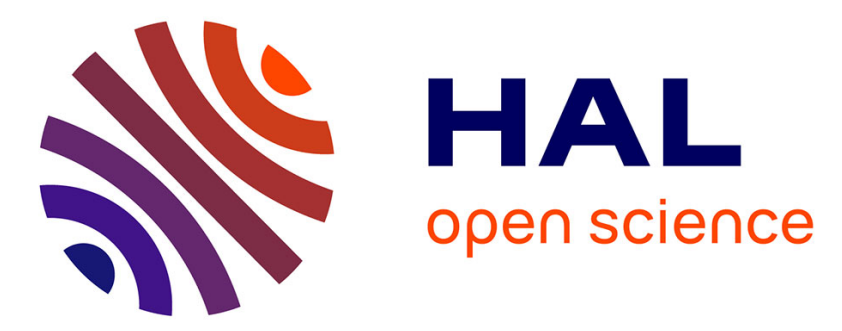

\title{
Use of Early Remedial Services in Children with Transposition of the Great Arteries
}

Johanna Calderon, Damien Bonnet, Charlotte Pinabiaux, Isabelle Jambaqué, Nathalie Angeard

\section{To cite this version:}

Johanna Calderon, Damien Bonnet, Charlotte Pinabiaux, Isabelle Jambaqué, Nathalie Angeard. Use of Early Remedial Services in Children with Transposition of the Great Arteries. The Journal of Pediatrics, 2013, 163 (4), pp.1105-1110.e1. 10.1016/j.jpeds.2013.04.065 . hal-03129813

\section{HAL Id: hal-03129813 \\ https://hal.parisnanterre.fr/hal-03129813}

Submitted on 3 Feb 2021

HAL is a multi-disciplinary open access archive for the deposit and dissemination of scientific research documents, whether they are published or not. The documents may come from teaching and research institutions in France or abroad, or from public or private research centers.
L'archive ouverte pluridisciplinaire HAL, est destinée au dépôt et à la diffusion de documents scientifiques de niveau recherche, publiés ou non, émanant des établissements d'enseignement et de recherche français ou étrangers, des laboratoires publics ou privés. 


\title{
Use of Early Remedial Services in Children with Transposition of the Great Arteries
}

\author{
Johanna Calderon, $\mathrm{MS}^{1}$, Damien Bonnet, $\mathrm{MD}, \mathrm{PhD}^{2}$, Charlotte Pinabiaux, $\mathrm{PhD}^{1}$, Isabelle Jambaqué, $\mathrm{PhD}^{1}$, \\ and Nathalie Angeard, $\mathrm{PhD}^{1}$
}

Objectives To characterize the prevalence of use of early remedial services and its associated demographic, medical, and cognitive factors in children aged 4-6 years with corrected transposition of the great arteries (TGA). Study design This was a prospective study of neurocognitive outcomes after TGA. Children underwent formal neu-ropsychological testing including general intelligence and a comprehensive battery of executive functions (EF) includ-ing motor and interference control, short-term memory, and working memory as well as cognitive flexibility. Parental reports on the children's behavior and EF were also evaluated. Demographic factors and preoperative, intraoperative, and postoperative factors as well as cognitive factors were examined according to the current use of remediation.

Results Forty-five patients (67\% male) and their parents participated in this study. Twenty-four (53\%) patients were receiving remedial services. Male sex, a postnatal diagnosis of TGA, and a longer postoperative intensive care unit stay were significantly associated with use of remediation. Children receiving remediation had lower EF scores, had more severe EF deficits as observed by formal testing, and were rated as having more behavioral daily life difficulties. However, in the group without remediation, 13 children $(43 \%)$ also displayed EF deficits rated as moderate to severe.

Conclusions Demographic and medical factors could help identify children at higher risk for neurocognitive delays. Evaluation of executive functioning from an early age may influence referral for remediation. ( $J$ Pediatr 2013;163:1105-10).

$\mathbf{P}$

rogress in survival rates and physical outcomes has led to the important recognition of neurobehavioral and cognitive impairments for children with congenital heart disease (CHD). The most recent studies suggest the presence of a distinctive neurodevelopmental pattern of dysfunction including mild motor deficits, impaired social interaction and communication skills, inattention, and deficits in executive functions (EF). ${ }^{1-4}$ These impairments can have detrimental repercussions on academic achievement, psychosocial development, and ultimately quality of life. ${ }^{1}$ It has been reported that nearly one-half of school-aged children with CHD were receiving some form of educational service ${ }^{5}$ and that $65 \%$ of adolescents with transposition of the great arteries (TGA) had a frequent history of special services use. ${ }^{6}$ However, very few studies have addressed this question systematically, and only 1 study focused on the pattern and characteristics of remedial service use, with only $23 \%$ benefiting from services. ${ }^{7}$

The prevalence and predictors of the use of remediation use at an earlier age where cognitive and behavioral impairments are emerging such as during the preschool years remain unknown. Children with CHD including TGA display significant behavioral and EF dysfunction ${ }^{2-4,8}$ observable even before entry to primary school. ${ }^{9}$ A high prevalence of hyperactivity/impulsivity symptoms consistent with attention-deficit hyperactivity disorder $(\mathrm{ADHD})^{5}$ has also been reported. EF including motor and interference control, short-term memory, and working memory as well as cognitive flexibility undergo crucial improvements in the preschool period and are important precursors of children's behavioral and social adaptation. ${ }^{10-12}$ These higher-order cognitive skills are strong predictors of later academic achievement including verbal and math learning in children. ${ }^{10-17}$ It has been shown that early interventions in children with cognitive disability promote greater achievement. ${ }^{18}$ The aim of this study was to characterize the prevalence of use of remedial services and associated factors in children with TGA. We sought to determine the association of demographic and pre-, intra-, and postoperative factors as well as cognitive outcomes to the use of early remedial services.

\section{Methods}

All neonates born with TGA between 2003 and 2005 and operated at the referral center for complex congenital heart malformations, Necker Children's Hospital

\footnotetext{
ADHD Attention-deficit hyperactivity disorder

CHD Congenital heart disease

EF Executive functions

ICU Intensive care unit

NEPSY Developmental Neuropsychological Assessment

TGA Transposition of the great arteries
}

From the ${ }^{1}$ Inserm U663, Paris, France; University Paris Descartes, Sorbonne Paris Cité, Assistance Publique Hôpitaux de Paris, Necker Hospital; and ${ }^{2}$ Referral Center for Complex Congenital Cardiac Malformations, University Paris Descartes, Paris, France

Supported by the Association pour la Recherche en Cardiologie du Foetus à l'Adulte (Association for Research in Cardiology from Fetus to Adults), Necker Children's Hospital, Paris, France. J.C. is supported by a university $\mathrm{PhD}$ fellowship. The authors declare no conflicts of interest.

0022-3476/\$ - see front matter. Copyright $\odot 2013$ Mosby Inc. All rights reserved. http://dx.doi.org/10.1016/j.jpeds.2013.04.065 
(Paris, France), were screened for participation in a single center prospective study of neurocognitive outcomes. $\mathrm{Pa}$ tients meeting inclusion criteria received a diagnosis of TGA with intact ventricular septum or ventricular septal defect and underwent a neonatal arterial switch operation under continuous full-flow cardiopulmonary bypass. Neonates with associated genetic syndromes (including 22q11 deletion), associated extra-cardiac pathologies or cardiovascular anomalies requiring aortic arch reconstruction, and the use of deep hypothermic circulatory arrest or additional open surgical procedures as well as neonates with a birth weight less than $2.5 \mathrm{~kg}$ were excluded. Children whose native language was not French and/or who were living outside the Paris area at the time of enrollment were also excluded from participation. Data from a control group of same aged children $(n=45)$ living in the same geographic area was used as a reference to compare the prevalence of remedial service use.

The institutional ethics committee of Necker Children's Hospital approved the protocol and informed consent. Eligible families were contacted by a letter explaining the aim of the study with telephone follow-up to further explain the protocol. Families who agreed to participate were scheduled for a 2 to 2.5-hour visit at the hospital, and written informed consent was obtained from the parent(s) and the child. A cognitive evaluation was performed on all children by a trained neurodevelopmental psychologist who did not review medical records before conducting the neuropsychological battery.

Cognitive assessment included a nonverbal IQ evaluation using the Columbia Mental Maturity Scale. ${ }^{19}$ Motor control was assessed with the knock and tap subtest from the Developmental Neuropsychological Assessment (NEPSY) ${ }^{20}$; interference control and impulse control were measured with the Animal Stroop test, ${ }^{21}$ a pictorial version of the Stroop task that does not require reading abilities. This test provides an evaluation of interference sensitivity and control of attention expressed by reaction times as well as an evaluation of cognitive impulse control skills expressed by the total number of incorrect responses. Verbal short-term memory and verbal working memory were assessed with the forward and backwards digit span subtests from the Wechsler Intelligence Scale for Children-fourth edition. ${ }^{22}$ Spatial immediate memory and spatial working memory were assessed with the spatial span task. $^{23}$ In this test, analogous to the verbal working memory task, the stimuli are visual (a set of small squares randomly positioned). Children reproduce a sequence of squares locations in the same order as they saw it and then backwards. Finally, cognitive flexibility was evaluated with the Dimensional Card Sorting Test, ${ }^{24}$ a well-known neuropsychological test for preschool children. Normative values for all tests were obtained from national standardizations and previous references published. ${ }^{2,9,21}$ Parental reports on the children's behavior and EF were obtained using the Behavior Rating Inventory of Executive Function-preschool and school-age versions $^{25}$ for children between 4 and 6 years 11 months. For this scale we analyzed the global executive composite score, a T score (expected mean $=50 ; \mathrm{SD}=10$ ) with a higher $\mathrm{T}$ score indicating greater impairment (Appendix; available at www.jpeds.com).

Information regarding remedial services use was gathered through parental reports during the visits. A short written survey with a multiple-choice format was used to collect diverse data regarding health status, demographic variables, and developmental information including current remedial service use. Patient's medical records were reviewed for potential risk factors associated with cognitive deficits and remedial service use. Preoperative medical factors included pre- vs postnatal diagnosis of TGA, presence or absence of a ventricular septal defect, birth weight, gestational age, Apgar score at 5 minutes, hemodynamic condition (metabolic acidosis defined with a $\mathrm{pH}$ level <7.2), and the need for balloon-atrial septostomy. Age at the arterial switch operation, total bypass time and total cross-clamp time, and postoperative intensive care unit (ICU) stay duration were also examined. Demographic variables including sex, age at evaluation, family socioeconomic status, and parental educational levels were also recorded.

\section{Statistical Analyses}

Statistical analyses were performed with Statistica software (v. 9.1; StatSoft Inc, Maisons-Alfort, France). Descriptive results are presented with means (SD) and proportions in each group. Demographic and medical variables were compared between groups by using $\chi^{2}$ tests for categorical variables and ANOVA for numerical variables. Differences in cognitive scores were assessed using ANOVA with posthoc testing (Tukey Honestly Significant Difference Test) for specific comparisons across groups for all continuous variables. Multivariate logistic regression analyses including separate analyses with demographic and medical variables were performed to identify significant predictors of remedial service use. Scores in each EF subtest were compared with normative values and deficits were described according to their severity as "mild" ( $-1 \mathrm{SD})$ or "moderate to severe" ( -2 SD or below). The total number of mild and moderate to severe deficits were calculated for each individual, each one ranging from $0=$ no deficits to $8=$ deficits in all $\mathrm{EF}$ subtests. Mean numbers of mild and moderate to severe deficits were then calculated for the groups (with and without remediation), and Poisson regression analyses were used for comparisons between the groups. Multiple logistic regression analyses were used to determine significant determinants (medical and demographic) once the severity of EF deficits was adjusted. A $P$ value of .05 was considered significant.

\section{Results}

A total of 60 eligible children born between 2003 and 2005 were identified in the database. Six families could not be contacted because of a change of address. Fifty-four families were contacted for enrollment in a single-center prospective study of neurocognitive outcomes. Parents of 6 children declined 
participation in the study, 2 children were excluded due to developmental disorders not previously identified (autism spectrum disorder and severe language disability), and 1 child refused to cooperate with the administration of the tests. Forty-five children participated in the study (mean age $=5$ years; $\mathrm{SD}=4$ months, 30 [67\%] males and 15 [33\%] females). No significant differences were found between participants and nonparticipants for all medical related variables (all $P>.05$ ).

Twenty-four (53\%) children with TGA were receiving at least 1 remedial service. Among children using remedial services $(\mathrm{n}=24), 15(62 \%)$ were receiving special educational support, $10(42 \%)$ were using speech and language therapy, 9 (37\%) psychology/psychiatry therapy, 4 (17\%) occupational therapy, and $2(8 \%)$ were followed-up by a pediatric neurologist.

No significant differences between the groups were found regarding children's age $(\mathrm{t}[43]=0.04 ; P=.96)$, parental socioeconomic status $(\mathrm{t}[43]=0.02 ; P=.98)$, or parental educational levels (father's [ $\mathrm{t}\{43\}=0.63 ; P=.53$ ); mother's [ $\mathrm{t}$ $\{43\}=0.81 ; P=.42])$. The proportion of males and females significantly differed between the groups $\left(\chi^{2}[1]=3.61 ; P=\right.$ $.05)$. A logistic regression analysis model including all demographic variables confirmed sex as the only significant demographic predictor for the use of remedial services (Walds $\chi^{2}$ $[\mathrm{dl}=1]=4.15 ; P=.04)$. Results are summarized in Table I. The prevalence of children with TGA using services (53\%) was significantly higher than that observed in a reference control group of same-aged children (18\%) $\left(\chi^{2}[1]=12.41 ; P=.0004\right)$ in which the majority were also boys $(75 \%)$. The results concerning medical related variables are presented in Table II.

In our sample, $29(64 \%)$ children were prenatally diagnosed with TGA against 16 (36\%) who were diagnosed after birth. All children with prenatal diagnosis were delivered on site; the median age at admission for those diagnosed postnatally was 16 hours. As shown in Table II, results indicated that the proportion of children prenatally diagnosed was significantly higher in the group without remedial services $\left(\chi^{2}[1]=4.68 ; P=.03\right)$. Moreover, ICU stay was significantly longer for the group with remedial services (Wald $\chi^{2}[1]=3.48 ; P=.05$ ). No other significant differences were found. A logistic regression analysis model including all categorical and numerical medical factors revealed that postnatal diagnosis of TGA and ICU stay significantly predicted the use of remedial services in this cohort (Wald $\chi^{2}[1]=5.53 ; P=.01$ and Wald $\chi^{2}[1]=$ $3.88 ; P=.04)$.

\section{Formal Testing}

ANOVA with post hoc testing (Tukey Honestly Significant Difference Test) for specific comparisons including all cognitive variables showed that children with TGA who were using remedial services had significantly lower scores in motor control $(P=.04)$, short-term spatial memory $(P$ $=.03)$, spatial working memory $(P=.01)$, and cognitive flexibility $(P=.04$; Table III $)$.
Table I. Group characteristics regarding sociodemographic variables

\begin{tabular}{lcr}
\hline & $\begin{array}{c}\text { Remedial } \\
\text { service }(\mathbf{n}=\mathbf{2 4})\end{array}$ & $\begin{array}{c}\text { No remedial } \\
\text { service }(\mathbf{n}=\mathbf{2 1})\end{array}$ \\
\hline Sex, \% males & $19(79 \%)^{\star}$ & $11(52 \%)$ \\
Age, m (SD) & $5.47(0.93)$ & $5.49(1.18)$ \\
SES, m (SD) & $1.96(0.95)$ & $1.95(0.90)$ \\
Father's educational level, m (SD) $^{\ddagger}$ & $3.3(1.60)$ & $3.0(1.39)$ \\
Mother's educational level, m (SD) $^{\ddagger}$ & $3.5(1.61)$ & $3.0(1.72)$
\end{tabular}

SES, socioeconomic status.

Values are $\mathrm{n}(\%)$ and means (SD).

${ }^{*} P<.05$ for comparisons between patients with and without remedial services. Analyses were calculated by using one-way ANOVAs and $\chi^{2}$ tests.

†Socioeconomic status was scored according to the index from the French National Demographic Statistical Institute in a scale from 0-3, with a higher score indicating a higher socioeconomic status.

$\ddagger$ Parental educational level was scored according to the French National Education Diploma classification $(0=$ primary school education; 1 = middle education; 2 = high school diploma; $3=$ college undergraduate; $4=$ college graduate/masters degree, and $5=$ postgraduate/doctoral degree).

More specifically, according to type of remediation, lower scores on motor control (Wald $\chi^{2}[1]=0.04$ ), interference control (Wald $\left.\chi^{2}[1]=0.009\right)$, short-term verbal (Wald $\chi^{2}$ $[1]=0.04)$, and spatial memory (Wald $\left.\chi^{2}[1]=0.05\right)$ were significantly associated with the use of special educational support. No other significant association with other types of remediation (language therapy, psychology/psychiatry therapy, occupational therapy, and neurologic follow-up) was found $(P>.05)$.

As deficits in EF are rarely isolated and their potential accumulation may suggest a higher cognitive risk, we sought to determine if the mean number of executive deficits across the $8 \mathrm{EF}$ components differed between the groups with and without remediation. As shown in Table III, children with TGA who were receiving remedial services did not have more cumulated mild EF deficits than those who had no current remedial service (Walds $\chi^{2}[1]=0.63 ; P=.42$ ). However, when compared on moderate to severe deficits, children currently using remedial services had significantly more cumulated EF deficits than children who were not using

Table II. Pre-, intra-, and postoperative factors according to remedial services use

\begin{tabular}{lcr}
\hline & $\begin{array}{c}\text { Remedial } \\
\text { service }(\mathbf{n}=\mathbf{2 4})\end{array}$ & $\begin{array}{c}\text { No remedial } \\
\text { service }(\mathbf{n}=\mathbf{2 1})\end{array}$ \\
\hline Prenatal diagnosis, $\mathrm{n}(\%)$ & $12(50 \%)^{*}$ & $17(81 \%)$ \\
Birth weight, kg & $3.25(0.49)$ & $3.23(0.42)$ \\
Gestational age, wk & $39.1(1.89)$ & $38.7(1.64)$ \\
Apgar score, 5 min & $8.5(1.75)$ & $9.2(0.85)$ \\
Associated VSD, $\mathrm{n}(\%)$ & $6(30 \%)$ & $8(38 \%)$ \\
Acidosis, $\mathrm{n}(\%)$ & $2(10 \%)$ & $2(10 \%)$ \\
Atrial septostomy, $\mathrm{n}(\%)$ & $14(70 \%)$ & $13(62 \%)$ \\
Age at surgery, d & $6.4(3.39)$ & $8.05(3.70)$ \\
Bypass time, min & $128.65(23.26)$ & $131.76(19.63)$ \\
Aortic clamp time, min & $84.1(16.01)$ & $86.3(11.53)$ \\
ICU stay, d & $7.25(5.68)^{*}$ & $5.76(2.77)$
\end{tabular}

$\checkmark S D$, ventricular septal defect.

One-way ANOVA and $\chi^{2}$ were used to determine significant differences between groups with and without remedial services for medical related variables.

${ }^{\star} P<.05$ for comparisons between patients with and without remedial services. 
Table III. Cognitive scores and total number of EF deficits according to the use of remedial services

\begin{tabular}{|c|c|c|c|}
\hline & & Remedial service $(n=24)$ & No remedial service $(n=21)$ \\
\hline Cognitive domain & Cognitive test & Mean (SD) & Mean (SD) \\
\hline IQ & Columbia Mental Maturity Scale & $110.3(7.15)$ & $111.9(8.89)$ \\
\hline Motor control & NEPSY-Knock/Tap & $23(4.49)^{*}$ & $25(2.30)$ \\
\hline Interference control & Stroop test (reaction time) & $84.1(32.54)$ & $80.49(31.20)$ \\
\hline Impulse control & Stroop test (number of errors) & $3.54(3.68)$ & $2.57(2.01)$ \\
\hline Short-term verbal memory & Digit span forward WISC-IV & $5.45(2.02)$ & $5.47(1.50)$ \\
\hline Verbal working memory & Digit span backwards WISC-IV & $2.50(2.73)$ & $3.23(2.18)$ \\
\hline Short-term spatial memory & BEM-144 spatial span forward & $4.08(1.24)^{\star}$ & $4.90(1.33)$ \\
\hline Spatial working memory & BEM-144 spatial span backwards & $2.33(2.03)^{*}$ & $3.90(1.94)$ \\
\hline Cognitive flexibility & DCST & $6.45(3.18)^{\star}$ & $8.2(2.19)$ \\
\hline Total mean number of EF mild deficits ( $-1 \mathrm{SD})(0-8)$ & - & $1.8(1.16)$ & $1.5(1.03)$ \\
\hline $\begin{array}{l}\text { Total mean number of EF moderate to severe deficits } \\
(-2 \text { SD or below) }(0-8)\end{array}$ & - & $2.4(2.06)^{*}$ & $1.09(1.44)$ \\
\hline
\end{tabular}

BEM-144, battery of memory efficiency 144 blocks; DCST, Dimensional Card Sorting Test; WISC-IV, Wechsler Intelligence Scale for Children-fourth edition. Mean scores with SD in parentheses.

${ }^{\star} P<.05$ for comparisons between patients with and without remedial services.

any remediation (Wald $\left.\chi^{2}[1]=10.81 ; P=.001\right)$. Moreover, despite the fact that deficits below -2 SD were less numerous in the group without remediation, analyses revealed than among these 21 children, $13(43 \%)$ had at least 1 moderate to severe EF deficit.

Finally, to determine if the factors associated with the remediation use remained significant once the severity of EF deficits was controlled, we conducted a multiple logistic regression analysis with adjustment for the severity of the EF dysfunction (number of deficits below $-2 \mathrm{SD}$ ). We included in this model all variables that were significantly associated with the use of remediation services (sex, postnatal diagnosis of TGA, and postoperative ICU stay). Analyses revealed that for children with similar severity of EF deficits, those who were diagnosed after birth still had a significantly higher prevalence of remediation use (Wald $\chi^{2}[1]=3.84 ; P=$ $.04)$. The significant effects of other factors did not remain once the severity of EF deficits was controlled.

The findings on the Behavior Rating Inventory of Executive Function reported a significantly higher general executive composite score indicating greater impairment for children with TGA currently receiving remedial services (m $=54.75 ; \mathrm{SD}=11.62)$ compared with those without current remediation $(\mathrm{m}=47.42 ; \mathrm{SD}=10.49)(\mathrm{F}[1,39]=6.28 ; P=$ $.01)$. In addition, the proportion of children in the whole cohort with scores greater than the cut-off for clinical concern (60) was $18 \%$. Among children in the clinical concern range, 4 out of 8 were not currently receiving remediation. Parents of children receiving special educational support and psychology/psychiatric therapy reported significantly more behavior and $\mathrm{EF}$ impairments $(\mathrm{F}[1,39]=6.41 ; P=.01 ; \mathrm{F}$ $[1,39]=25.2 ; P=.00001)$.

\section{Discussion}

Our results show that $53 \%$ of the children in our cohort received at least 1 remedial service. This percentage was significantly higher than that observed in a same-aged control group recruited in the same geographic area (18\%). In the
Boston Circulatory Arrest Trial, ${ }^{8}$ more than one-third of children with TGA aged 4-8 years were evaluated by a speech pathologist, one-sixth by an occupational therapist, and less than $10 \%$ by a psychiatrist and by a physical therapist. No information regarding associated patient-related factors to the use of these services was provided. ${ }^{8}$ Our proportion using remediation at a mean age of 5 is higher than the proportion reported in children with various types of CHD aged 8 $(23 \%) .{ }^{7}$ In this later study, the majority of developmentally delayed children were not receiving any resource support. In France, systematic general pediatric and developmental examinations of all preschool children before the transition to primary school may help refer children with important delays (eg, language or psychomotor) with or without EF dysfunction. However, mild deficits and specific impairments in attention and EF, when not associated with other disabilities, can easily go undetected.

Our results demonstrate that male sex was significantly associated with remedial service use. Boys with CHD have been reported to be twice as likely to exhibit neurologic abnormalities on examination as well as poorer fine motor skills. They were at significantly greater risk for dependency in functional daily tasks (self care, age-appropriate communication skills, problem solving tasks). ${ }^{26}$ Evidence of a male disadvantage has been reported in preterm infants ${ }^{27}$ and in very low birth weight preterm male neonates who presented worse neurologic outcomes and higher rates of abnormal neurodevelopment compared with female neonates. ${ }^{28}$ However, it is worth noting that the majority of children requiring remediation in the reference group in Paris region are also boys (75\%) suggesting that the gender difference in the CHD population may perhaps only reflect the fact that males are generally more likely to require these services.

Data from this study also demonstrate that a postnatal diagnosis of TGA and longer postoperative ICU stay are significantly associated with the use of remediation. These results support previous findings indicating a beneficial impact of prenatal diagnosis of TGA on neurocognitive results. ${ }^{9,29}$ Delayed diagnosis of the cardiac condition may 
be a surrogate for vulnerability as children diagnosed after birth display more adverse neonatal risk factors ${ }^{29}$ including a higher incidence of preoperative acidosis. ${ }^{9}$

In our sample, children who were receiving remedial services had significantly worse scores on motor control, spatial short-term, and working memory, as well as on cognitive flexibility. More specifically, motor and interference control, short-term verbal memory, and spatial memory were significantly associated with special educational support use, suggesting a relationship between EF vulnerability and general early learning difficulties. Moreover, parental reports on children's everyday behavioral and EF difficulties were also found to be significantly associated with remediation use. In typical early childhood, difficulty with selfregulation and delay in EF maturation (rather than general intelligence levels) are main causes of lack of school readiness. ${ }^{30}$ Children with TGA who display EF impairments may encounter difficulties in various aspects of academic and daily life including problem solving, retaining pertinent information, focusing attention, shifting between alternatives, and carrying out step-by-step processes. Our analyses revealed a significant effect of cumulating multiple moderate to severe deficits in EF on receiving developmental remediation. However, not receiving rehabilitation or educational services does not necessarily reflect an absence of dysfunction as 13 children in the group without remediation still presented at least one important $\mathrm{EF}$ deficit.

A scientific statement from the American Heart Association categorized children requiring open-heart surgery at high risk for developmental disorders or disabilities and recommended that they should be referred for formal developmental and medical evaluations at key stages where important transitions are made such as school-age and adolescence. ${ }^{4}$ Evaluations should ideally also include early identification of specific behavioral and executive impairments that may have a direct impact on the onset of interventions for these patients. Parental reports and formal assessments of these domains before primary school entry have demonstrated to be good indicators of further learning and adaptation disabilities and therefore should be considered when evaluating young children with CHD. It has been demonstrated that training of working memory and executive control through computerized programs can result in significant improvement in these abilities $^{31}$ and also may have a positive impact on emotional and social development. ${ }^{32}$

Results from this study should be considered in light of several limitations. TGA constitutes a cardiac defect successfully corrected in the neonatal period, and therefore, our results concerning the prevalence and factors associated with remediation utilization may not be generalized to all children with CHD. However, including a sample with very homogeneous medical characteristics allowed us to control for adverse variables such as chronic hypoxemia, number of operations, or hospitalizations. The predictive value of other potential isolated or associated language or psychomotor delays on the use of services remains to be investigated. Differences in health care accessibility and insurance coverage should be taken into account when interpreting these findings as the prevalence of remediation use may also be highly dependent on resources available to families according to geographic and cultural settings.

Clearly, consequences of neurocognitive morbidities associated with CHD should become a high priority in these patients' follow-up. Particular attention should be drawn to early surveillance, screening, evaluation of specific cognitive and behavioral difficulties including executive functioning.

The authors thank all the families who participated in this study.

Submitted for publication Jan 7, 2013; last revision received Mar 28, 2013; accepted Apr 30, 2013.

\section{References}

1. Bellinger D, Newburger J. Neurospychological, psychosocial and quality-of- life outcomes in children and adolescents with congenital heart disease. Progress Pediatr Card 2010;29:87-92.

2. Calderon J, Bonnet D, Courtin C, Concordet S, Plumet M-H, Angeard N. Executive function and theory of mind in school-aged children after neonatal corrective cardiac surgery for transposition of the great arteries. Dev Med Child Neurol 2010;52:1139-44.

3. Hövels-Gürich HH, Konrad K, Skorzenski D, Herpertz-Dahlmann B, Messmer BJ, Seghaye M- C. Attentional dysfunction in children after corrective cardiac surgery in infancy. Ann Thorac Surg 2007;83:142530.

4. Marino BS, Lipkin PH, Newburger JW, Peacock G, Gerdes M, Gaynor JW, et al. Neurodevelopmental outcomes in children with congenital heart disease: evaluation and management a scientific statement from the American Heart Association. Circulation 2012;126:1143-72.

5. Shillingford AJ, Glanzman MM, Ittenbach RF, Clancy RR, Gaynor JW, Wernovsky G. Inattention, hyperactivity, and school performance in a population of school-age children with complex congenital heart disease. Pediatrics 2008;1:759-67.

6. Bellinger DC, Wypij D, Rivkin MJ, DeMaso DR, Robertson RL Jr, Dunbar-Masterson C, et al. Adolescents with d-transposition of the great arteries corrected with the arterial switch procedure: neuropsychological assessment and structural brain imaging. Circulation 2011;20:1361-9.

7. Majnemer A, Mazer B, Lecker E, Leduc Carter A, Limperopoulos C, Shevell M, et al. Patterns of use of educational and rehabilitation services at school age for children with congenitally malformed hearts. Cardiol Young 2008;18:288-96.

8. Bellinger DC, Wypij D, duPlessis AJ, Rappaport LA, Jonas RA, Wernovsky G, et al. Neurodevelopmental status at eight years in children with dextro-transposition of the great arteries: the Boston Circulatory Arrest Trial. J Thorac Cardiovasc Surg 2003;126:1385-96.

9. Calderon J, Angeard N, Moutier S, Plumet M-H, Jambaqué I, Bonnet D. Impact of prenatal diagnosis on neurocognitive outcomes in children with transposition of the great arteries. J Pediatr 2012;161:94-8.

10. Bull R, Espy KA, Wiebe SA. Short-term memory, working memory, and executive functioning in preschoolers: longitudinal predictors of mathematical achievement at age 7 years. Dev Neuropsychol 2008;33:205-28.

11. Diamond A, Barnett WS, Thomas J, Munro S. Preschool program improves cognitive control. Science 2007;30:1387-8.

12. Hughes C, Ensor R. Does executive function matter for preschoolers' problem behaviors? J Abnorm Child Psychol 2008;36:1-14.

13. Monette S, Bigras M, Guay M-C. The role of the executive functions in school achievement at the end of grade 1. J Exp Child Psychol 2011;109: 158-73.

14. Johnson S, Wolke D, Hennessy E, Marlow N. Educational outcomes in extremely preterm children: neuropsychological correlates and predictors of attainment. Dev Neuropsychol 2011;36:74-95. 
15. Rose SA, Feldman JF, Jankowski JJ. Modeling a cascade of effects: the role of speed and executive functioning in preterm/full-term differences in academic achievement. Dev Sci 2011;14:1161-75.

16. Marton K. Visuo-spatial processing and executive functions in children with specific language impairment. Int J Lang Commun Disord 2008;43: 181-200.

17. Diamantopoulou S, Rydell A-M, Thorell LB, Bohlin G. Impact of executive functioning and symptoms of attention deficit hyperactivity disorder on children's peer relations and school performance. Dev Neuropsychol 2007;32:521-42.

18. Majnemer A, Shevell MI, Rosenbaum P, Abrahamowicz M. Early rehabilitation service utilization patterns in young children with developmental delays. Child Care Health Dev 2002;28:29-37.

19. Burgemeister L, Blum H, Lorge I. Columbia Mental Maturity Scale. New York: Psychological Corporation; 1972.

20. Korkman M, Kirk U, Kemps S. NEPSY: A developmental neuropsychological assessment manual. San Antonio, TX: Psychological Corporation; 1998.

21. Wright I, Waterman M, Prescott H, Murdoch-Eaton D. A new Strooplike measure of inhibitory function development: typical developmental trends. J Child Psychol Psychiatry 2003;44:561-75.

22. Wechsler D. Manual of Wechsler Intelligence Scale for Children-fourth edition. New York: Psychological Corporation; 2003.

23. Berch DB, Krikorian R, Huha EM. The Corsi block-tapping task: meth odological and theoretical considerations. Brain Cogn 1998;38:317-38.
24. Zelazo PD. The Dimensional Change Card Sort (DCCS): a method of assessing executive function in children. Nat Protoc 2006;1:297-301.

25. Gioia GA, Isquith PK, Guy SC, Kenworthy L. Behavior rating inventory of executive function. Child Neuropsychol 2000;6:235-8.

26. Majnemer A, Limperopoulos C, Shevell M, Rohlicek C, Rosenblatt B, Tchervenkov C. Gender differences in the developmental outcomes of children with congenital cardiac defects. Cardiol Young 2012;22:514-9.

27. Kent AL, Wright IMR, Abdel-Latif ME. Mortality and adverse neurologic outcomes are greater in preterm male infants. Pediatrics 2012; 129:124-31.

28. Rose J, Butler E, Lamont L, Barnes P, Atlas S, Stevenson D. Neonatal brain structure on MRI and diffusion tensor imaging, sex and neurodevelopment in very-low-birth weight preterm children. Dev Med Child Neurol 2009;51:526-35.

29. Bonnet D, Coltri A, Butera G, Fermont L, Le Bidois J, Kachaner J, et al. Detection of transposition of the great arteries in fetuses reduces neonatal morbidity and mortality. Circulation 1999;23:916-8.

30. Blair C, Diamond A. Biological processes in prevention and intervention: the promotion of self-regulation as a means of preventing school failure. Dev Psychopathol 2008;20:899-911.

31. Rueda MR, Rothbart MK, McCandliss BD, Saccomanno L, Posner MI. Training, maturation, and genetic influences on the development of executive attention. Proc Natl Acad Sci U S A 2005;102:14931-6.

32. Diamond A, Lee K. Interventions shown to aid executive function development in children 4 to 12 years old. Science 2011;19:959-64. 


\section{Appendix}

The Columbia Mental Maturity Scale ${ }^{19}$ is an individually administered test designed to assess the general reasoning ability of children from the age of 3-9 years. This test includes 100 pictorial and figural classification items arranged in levels of complexity. It evaluates general nonverbal intellectual abilities. Raw scores are converted to a standard IQ with a mean of 100 and a SD of 15 .

The NEPSY is a developmental neuropsychological assessment battery. ${ }^{20}$ Each subtest assesses a specific neuropsychological domain for children from 3-12 years old. Knock and Tap Subtest, assess the capacity to control motor actions in response to a contradictory visual stimulus. The child learns a pattern of motor sequences and has to inhibit the automatic tendency to imitate the experimenter's contradictory motor actions. Validity studies show that there is a weak correlation between the executive function subtests of the NEPSY and tests of general intelligence. NEPSY is commonly used in clinical populations including children diagnosed with ADHD. Subtests of EF have been described as good predictors of attention and hyperactivity disorders.

Animal Stroop test ${ }^{21}$ is used to assess cognitive inhibition capacities in young children from 3 years old. It consists of a pictorial version of the Stroop task, and it does not require reading abilities. It was designed to be sensitive to individual and age-related differences in impulse control and visual interference sensitivity. Visual stimuli (4 exemplar images of animals) are congruent in the first condition, neutral in the second condition, and then incongruent in the third condition, where each animal's head is substituted with another animal's head. Interference is elicited from the well documented preferential processing of facial information over body information. Children are required to name the body and inhibit a preferred response based on the identification of the animal's head. Scores are given in terms of reactions times as well as the number of errors committed. Validity studies of populations with frontal lobe epilepsy, traumatic brain injury, or ADHD support this task as a sensitive measure of cognitive inhibition.
Digit span is a subtest from the Wechsler Intelligence Scale for Children-fourth edition ${ }^{22}$ It measures verbal working memory skills: retaining and manipulating information for a short time. It includes 2 parts: forwards and backwards. The forward part requires the child to repeat numbers as they were stated by the experimenter, whereas the backward part requires the child to repeat in the reverse order as they were stated. If scores in the forward part are within the normal range, digit span backwards is taken as the reference for verbal working memory. In the spatial span task, ${ }^{15}$ analogous to the verbal working memory task, the stimuli are visual (a set of small squares randomly positioned). Children reproduce a sequence of squares locations in the same order as they saw it and then backwards.

Dimensional Card Sorting Test ${ }^{24}$ is a widely used measure of cognitive flexibility capacities in young children. Children are required to sort a series of bivalent cards, first according to one dimension (eg, shape), then according to the other (eg, color), and finally a combination of trials with rapid switches between dimensions. Performances progressively increase between 4 and 6 years and are commonly impaired in children with ADHD, prefrontal cortical damage, and autism.

Behavior Rating Inventory of Executive Functionpreschool and school-age versions ${ }^{25}$ is a questionnaire for parents of children aged 2 and one-half to 5 years (preschool version) and children aged 5-18 years (school-age version). It assesses executive function behavior in the home and school environments. Validity studies have been conducted on various pediatric populations including children with learning disabilities and attention disorders, traumatic brain injuries, lead exposure and other developmental, neurologic or and medical conditions. The parent forms contain 63 items for the preschool version and 86 items for the school age version, both measuring different aspects of executive functioning: inhibition, shifting, emotional control, working memory, organization and planning skills, organization of materials, and monitoring abilities. Raw scores are converted to a standard score named Global Executive Composite with a mean of 50 and a SD of 10 . 